themselves in the original texts. Quite apart from his scientific skills, Cuvier was also a remarkable writer. Eager to convince, he had an accurate, clear, elegant style and a great sense of drama that allowed him to draw striking and even sometimes dramatic portraits of vanished worlds.

Throughout this book, Rudwick reveals the interest that can be found in reading the texts written by a man of science whose ideas and concepts deeply influenced nineteenth century society and who helped to raise the international status of anatomy and geology as professions.

Philippe Taquet is in the Laboratoire de Paléontologie, Muséum National d'Histoire Naturelle, 8, rue de Buffon, 75005, Paris, France. e-mail:taquet@mnhn.fr

\section{Radical remedies}

\section{The Antidepressant Era}

by David Healey

Harvard University Press: 1998. Pp. 317. $\$ 39.95, £ 19.98$

\section{Leslie Iversen}

Over the past 50 years the discovery of drugs that effectively treat the symptoms of schizophrenia, anxiety and depression has revolutionized treatment and led to radical changes in the way we view mental illnesses. David Healey's book focuses on the discovery and development of antidepressants and provides a fascinating insight into the history of this field. He skilfully interweaves his account of the roles played by the key scientists and clinicians with the powerful influence of pharmaceutical companies.

The first antidepressants were discovered, by accident, on each side of the Atlantic in the mid-1950s. The Swiss company CIBA tested imipramine in schizophrenia because the drug had been designed to resemble in chemical structure the first anti-schizophrenic agent, chlorpromazine. Although imipramine proved ineffective in the treatment of schizophrenia, an astute psychiatrist, Roland Kuhn, thought it had euphoriant or stimulant effects in some of his patients and he persuaded the reluctant company to test it in depression where it proved highly successful.

In the United States, meanwhile, anecdotal reports that the drug iproniazid had euphoriant effects in some of the tuberculosis patients for which it was developed were followed up by Nathan Kline, already famous for his work on reserpine in schizophrenia. Kline persuaded Roche to conduct a trial in withdrawn depressed patients which proved highly successful. Kline, a skilful publicist, released the story to The New York Times and lobbied senior executives at Roche for continuing support. Although iproniazid and other monoamine oxidase inhibitors (MAOI) quickly fell out of favour because of their associated cardiovascular hazards (the 'wine-and-cheese' effect), they had a major impact as the first effective antidepressants in the United States. Kline was instrumental in lobbying Congress for funds to support psychopharmacology research and by the mid-1960s he had appeared on the cover of Fortune magazine and had become one of the ten best known men in America.

The MAOI were soon followed by amitriptyline, developed by the American company Merck and like imipramine because it chemically resembled chlorpromazine. The American psychiatrist Frank Ayd, however, had heard about Kuhn's results with imipramine and persuaded Merck to do trials in depression, which proved successful. Ayd also published an influential book on how to diagnose depression in general psychiatric practice, which helped to make amitriptyline the first antidepressant with major sales.

The drugs were expanding the diagnostic borders of depression, leading to the understanding that depression was far commoner than previously thought. This process reached its ultimate conclusion with Prozac and the concept that it could make some people feel "better than well".

Healey has perceptive insights into the role of the pharmaceutical industry in the development of the psychopharmacology era, and he portrays the often dramatic rises and falls in the fortunes of individual companies. He is at his best, though, in describing the shenanigans let loose by the drug era in his own profession, psychiatry. The advent of effective drug treatments led to major changes in this branch of medicine - introducing for the first time the concept of the controlled clinical trial and 'evidence-based medicine?.

There were often intense clashes between different ideologies (defined by Healey as "distinguished by their judgement of what ought to be regardless of what actually exists"). The psychoanalysts who dominated the profession in the 1950s and 1960s were pitted against the new biologically dominated school who embraced the use of the new drugs and called for radical changes in the classification of mental disorders. The two ideologies were often far apart - in many US psychiatric hospitals the psychotherapists refused to be associated with prescribing drugs for their patients, leaving this distasteful job to the "druggists" employed by hospitals. Eventually there emerged a backlash against the drug era in the form of "pharmacological Calvinism" - the belief that drug use is bad or even potentially dangerous if it makes you feel good.

The rise of psychopharmacology as a new field of research accompanied the drug era.

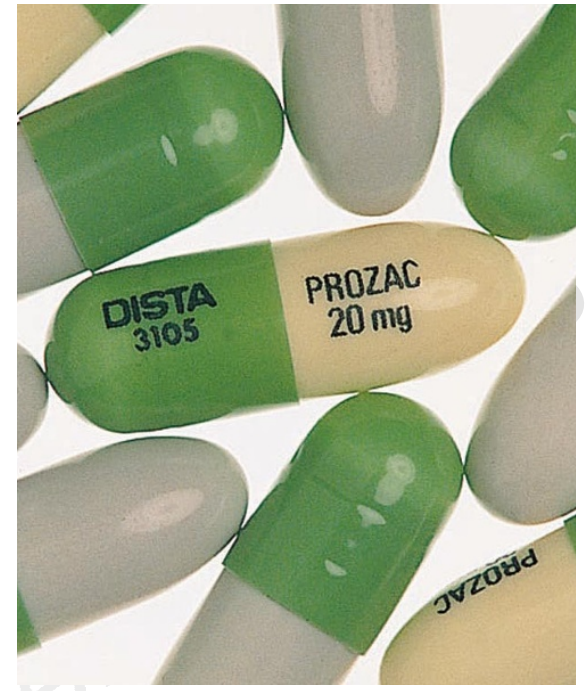

Superpill: Prozac-takers felt "better than well".

The "monoamine era" was heralded by the early discovery that reserpine acted by depleting monoamine neurotransmitters from the brain. This was followed by the finding that monoamine oxidase inhibitors and the tricylic antidepressants (imipramine and amitriptyline) acted by making monoamines more available in the brain (by blocking the degrading enzyme or the tissue reuptake processes respectively). In the 1960 s and 1970s the 'noradrenaline hypothesis' of depression dominated, although extensive attempts to provide evidence for the underactivity of brain noradrenaline systems predicted by this hypothesis in depressed patients all failed. Nevertheless, the hypothesis seemed to gain support from the discovery that new drugs that targeted noradrenaline reuptake (desipramine and maprotiline) proved clinically effective as antidepressants.

Twenty years later, however, this idea was conveniently forgotten as the selective serotonin reuptake inhibitors, of which fluoxetine (Prozac) is the best known, came to the fore. This apparent paradox perhaps reveals the naivety of the simplistic monoamine theories of the 1960s and 1970s, which reached their peak with the notion of one monoamine for each major illness: noradrenaline for depression, serotonin for anxiety, dopamine for schizophrenia and acetylcholine for dementia!

The antidepressant era represents one of the seminal events in the social and cultural history of the latter half of the twentieth century. This book is written in an individual and engaging style and the author reveals a deep knowledge of his subject; he has his own firm views but does not force them upon the reader. I found it a compelling read and hope that it will reach a wide audience.

Leslie Iversen is in the Department of

Pharmacology, University of Oxford, Oxford OX1 3QT, UK. 